Ol'ha Ya. IVASIUK,

PhD (Philology), Associate Professor, Foreign Languages and Translation Chair, Yuriy Fed'kovych Chernovtsy State University; 2 Kotsiubynskoho st., Chernovtsy, 58012, Ukraine; tel.: +38 (0372) 550646; e-mail: aloguy@inbox.ru; ID ORCID: 0000-0001-6638-2652; Researcher ID: I-9485-2018.

\title{
DECODING OF VERSE ICONICITY IN THE CONTEXT OF HOLISTIC TRANSLATION
}

Summary. The object of the article is the problem of iconicity decoding of modern Canadian poetry in the context of holistic translation. The subject of this study is the specificity of Margot Osborn's poems translation into Ukrainian. The purpose of the article is to investigate the peculiarities of the iconicity decoding of modern Canadian poetry into Ukrainian. Methodology comprises the complex application of research methodologies, including descriptive, comparative and holistic methods, as well as semantic-stylistic and hermeneutical analyzes that made it possible to establish the basic approaches to decoding iconicity of contemporary Canadian poetry into Ukrainian. At the same time, the hypothesis about the necessity of applying a holistic approach for decoding poetry texts, as well as for determining the degree of their reproducibility is expressed. The latter are finding of research. The practical value of the investigation is systematic representation of the main types of iconicity in the poetry of Margot Osborn which was demonstrated for the first time. The dominant ways of Margot Osborn's poetry decoding into the Ukrainian language were carried out by the author of this study. Conclusions. It has been proved that the decoding of the iconicity of poetry is considered to be adequate only by the application of such method of decoding, when not separate components of poetry are saved, but their combination and interaction, in other words, the synergy leading to the emergence of a unique artistic and aesthetic whole.

Key words: decoding, iconicity, holistic approach, post non-classical approach, synergy.

Статтю отримано 30.04.2018 p.

http://dx.doi.org/10.18524/2307-4558.2018.29.139373

УДК [811.161.1+811.18]'362'366.59'373.4

МИХАЙЛЕНКо-зоТо Елена Александровна,

аспирант кафедры русского языка Одесского национального университета имени И. И. Мечникова; Французский бульвар, 24/26, г. Одесса, 65058, Украина; ст. преподаватель кафедры славяно-балканских языков, координатор отделения русского языка Тиранского университета; ул. Эльбасан, г. Тирана, Албания; тел: +35542452610; e-mail: olena.zoto@gmail.com; ORCID ID: 0000-0001-7733-0217

\section{НЕКОТОРЫЕ СРЕДСТВА ВЫРАЖЕНИЯ АДМИРАТИВНОЙ МОДАЛЬНОСТИ И СПОСОБЫ ЕЁ СОХРАНЕНИЯ В ПЕРЕВОДЕ (НА МАТЕРИАЛЕ АЛБАНСКОГО И РУССКоГо ЯзЫКОВ)}

Аннотация. Цель статьи - выявить специфические средства выражения адмиратива, а также установить некоторые возможные переводческие решения. Объект изучения - функционально-семантическая категория адмиратива, объединяющая разноуровневые средства выражения удивления в албанском и русском языках. Предметом исследования является интерпретация модальности адмиратива, анализ сходных и специфических языковых средств выражения модального значения удивления в двух языках, тождества и трансформы, используемые при переводе. Результатом исследования стало обнаружение того, что средства выражения адмиратива в албанском и русском языках оказываются разными: в албанском языке средства выражения удивления объединяются в грамматическую категорию адмиратива, в русском же эмоция удивления выражается лексически, в основном вводными словами. Трудности при переводе модального значения удивления связаны именно с асимметрией в средствах выражения сематической категории адмиративности в двух языках. Выводы. Категория адмиратива, выделенная в албанском и русском языках, имеет как общие для двух языков, так и некоторые специфические, свойственные одному из них, средства выражения. В подавляющем большинстве случаев перевода отмечается прагматическая тождественность оригиналу. Несовпадение средств выражения модальности адмиратива нередко приводит к нарушению прагматического потенциала языковых единиц или к неточному раскрытию адмиративной модальности в переводах. Практическая значимость исследования состоит в возможности установления основных особенностей перевода этой семантический категории для использования полученных результатов в преподавательской работе при подготовке преподавателей русского и албанского языков, а также переводчиков с русского языка на албанский и с албанского на русский. Кроме того, полученные данные могут быть использованы для совершенствования компьютерных переводческих программ с русского языка на албанский и наоборот.

Ключевые слова: адмиратив, функционально-семантическая категория, перевод, объективная модальность, субъективная модальность, русско-албанский перевод.

Постановка проблемы. Модальность является одной из основных категорий языка. Категория модальности реализуется в высказывании единицами, принадлежащими к различным языковым уровням: морфологическому, синтаксическому, лексическому, просодическому, а также комбинаци- 
ями этих единиц, среди которых вводные слова и обороты, модальные глаголы и наречия, специальные формы наклонений. Для русских, изучающих албанский язык, и для албанцев, изучающих русский язык, особую трудность представляет адмиративная модальность. Под термином “адмиративность) понимается лингвистическая категория, выражающая восхищение или удивление говорящего фактом, внезапно установленным им непосредственно до момента речи (эпистемическая неожиданность); в этом случае полученное знание контрастирует с предыдущим состоянием незнания. Это значение рассматривается в качестве особой категории “(ад)миратива» либо в рамках категории (эвиденциальности» [5, с. 311].

Трудности в способах выражения адмиративной модальности в русском языке возникают у албанцев, а албанского языка - у русских, прежде всего, из-за различий в культурно-национальном восприятии эмоций удивления и в отражении семантики адмиратива в языке, являющемся этническим элементом сознания его носителей. Главная причина трудностей в усвоении способов выражения адмиративной модальности заключается в том, что в албанском языке она объективируется грамматически, выражаясь формами особого наклонения, то есть адмиративная модальность в албанской языковой картине мира является одной из форм объективной модальности, в русском же языке адмиративная модальность является разновидностью лишь субъективной модальности, так как обычно реализуется лексическими средствами, которые структурируют соответствующее фонкционально-семантическое поле. В устной речи средством реализации адмиративности как модальной категории является также интонация, а в письменной - пунктуация. Решение вопроса о соотношении способов выражения восхищения и удивления в албанском и русском языках актуально и для фундаментальных, и для прикладных лингвистических исследований. Важным является установление соотносительных пар и их вариантов в сопоставляемых языках, выявление когнитивных оснований для выражения данного типа отношений теми или иными способами носителями албанского и русского языков, некоторые другие вопросы. Всё это должно служить оптимизации приёмов усвоения русского языка албанцами и албанского языка русскими, а также для совершенствования переводческих приёмов.

Анализ исследований и публикаций по исследуемой проблеме. Для Шарля Балли модальность это душа предложения, и, как и мысль, она образуется, в основном, в результате активной операции говорящего субъекта. Учёный считал, что в любом высказывании реализуется противопоставление фактического содержания (диктума) и индивидуальной оценки излагаемых фактов (модуса) [1, с. 44]. Рассматривая вопрос о модальности, академик В. В. Виноградов пишет, что каждое предложение включает в себя модальное значение как существенный конструктивный признак, то есть содержит в себе указание на отношение к действительности. Любое целостное выражение мысли, чувства, побуждения, отражая действительность в той или иной форме высказывания, облекается в одну из существующих в данной системе языка интонационных схем предложения и выражает одно из синтаксических значений, которые в своей совокупности образуют категорию модальности [3, с. 55-56]. В «Русской грамматике) (1980) термин (модальность) обозначает (разные явления, объединяемые тем признаком, что все они так или иначе - грамматически, лексически, интонационно - выражают отношение говорящего к сообщаемому или сообщаемого к действительности») [6, т. 2, с. 214].

А. В. Бондарко и его последователи модальность интерпретируют как функционально-семантическую категорию, выражающую разные виды отношения высказывания к действительности. При рассмотрении различных типов модальных значений центр тяжести переносится в этом случае на анализ модальной семантики на уровне высказывания [2, с. 264].

В работах многих лингвистов проводится разграничение объективной и субъективной модальности. Во-первых, речь идёт о модальных значениях действительности (имеет место, имело ли место, будет ли иметь место сообщаемое; разная степень вероятности, необходимости или достоверности её осуществления) и, во-вторых, о разных субъективных установках говорящих (согласие, несогласие, возражение, предположение, сомнение, удивление, желание, уверенность) [4, с. 67]. При объективной модальности выражаемое значение является грамматическим, поскольку имеет формы выражения в грамматической парадигме предикативной единицы. Субъективная модальность лишена таких парадигматических отношений.

Термины (адмиратив» и (адмиративность) были введены в 1878 г. филологом-балканистом Огюстом Дозоном при изучении соответствующих глагольных форм албанского языка. Выбор названия (фp. admiratif), происходящего от глагола со значением (восхищаться) (фp. admirer), Дозон объясняет тем, что описываемые формы имеют “особое значение восхищения или удивления, порой иронического ) [9, р. 226-227].

Ряд исследователей полагает, что адмиратив должен быть обособлен от категории эвиденциальности, поскольку в его семантике не содержится ни указания на источник информации, ни значения пересказа, ни приписывания той или иной степени вероятности сообщаемой информации [7]. По сравнению же с индикативным наклонении адмиратив выражает новую, неожиданную информацию [10, p. 185-200].

Ш. Демирай пишет, что албанский адмиратив как самостоятельное глагольное наклонение по своей структуре не имеет аналогов ни в одном другом индоевропейском языке. Даже при исполь- 
зовании подобной структуры в болгарском и македонском языках она реализуется лишь частично с так называемым (пересказыванием), которое используется для выражения удивления говорящего $[8$, f. 906].

Постановка исследовательских задач. В данной статье мы ограничиваемся рассмотрением модальной семантики адмиративности и изучаем только языковые средства выражения модальной семантики удивления в албанском и русском языках, а также трудности передачи такого типа модальности при переводе с одного языка на другой. Следовательно, целью исследования является выявление специфических средств выражения адмиратива в русском и албанском языках. Объектом нашего исследования является функционально-семантическая категория адмиратива, объединяющая разноуровневые средства выражения удивления в албанском и русском языках. Предмет изучения - анализ сходных и специфических языковых средств выражения модального значения удивления в двух языках и интерпретация адмиративной модальности, тождества и трансформы, используемые при переводе.

Изложение основного материала. Эмоция удивления является универсальным компонентом духовной культуры, которая в разных языках выражается по-разному. Именно субъективизм в интерпретации окружающей нас действительности обусловливает и специфические способы выражения. Одна и та же действительность может вызвать у говорящего разное эмоциональное отношение, и эта же действительность может оцениваться с разных сторон. Следовательно, сообщаемое может приобрести различные эмоциональные характеристики.

Сопоставляя функционально-семантические зоны адмиративности в албанском и русском языках, сразу бросается в глаза специфическая структура семантики адмиратива в албанском. Ядром (центром) поля в албанском языке служит морфологическое наклонение адмиратива. Глагольные формы адмиратива показывают реальное действие, сопровождающееся выражением удивления говорящего. Самыми употребительными формами удивления в албанском языке являются: настоящее время (lakam), прошедшее время (lakësha, paskam larë, paskësha larë). Эти формы удивления, соответствующие формам русского глагола мымъ, помимо модального значения, связанного с моментом речи, имеют соответствующие временные значения [8, f. 913].

В отличие от албанского, русский язык не имеет особых морфологических средств для выражения модального значения удивления. Если мы исключим интонацию как универсальный способ выражения модальных значений (в устной речи), функционально-семантическое поле адмиратива в русском языке окажется формируемым, как правило, лексическими средствами: вводными словами типа оказывается, наверное, видно и т. п., - которые выражают отношение говорящего (пишущего) к тому, о чём он говорит (пишет). Естественно, эти средства присутствуют и в албанском языке, но они являются периферийными элементами данного функционально-семантического поля.

Поскольку модальность является одним из обязательных компонентов высказывания, то перевод не может считаться адекватным, если в нём не сохранена модальность текста источника. Игнорирование модальной семантики сделало бы невозможным понимание сути самого процесса перевода и переводческих преобразований.

Как правило, модальные значения в переводе передаются теми же средствами, что и в оригинале. Но в нашем случае в русском языке нет особых глагольных форм для выражения модального значения удивления. Для выражения этого значения русский язык в основном использует лексические средства, которые с функциональной точки зрения служат показателями этой модальности.

Перейдем к рассмотрению некоторых случаев интерпретации глагольных форм адмиратива албанского языка и передачи их значений в русском языке. Примеры взяты из албанской и русской художественной литературы. Вот несколько примеров:

1) - Mos u nxeh, - u përgjegj vajza... Si thua ti të mos flasim fare?

- Unë dashkam qё ju të mos flisni fare, kështu?

- Mama, ti sonte je nervoze. Më mirë qetësohu njëherë... (K. Blushi, Ne shtëpinë tonë, f. 145).

- Не кипятись!- сказала девушка... Или ты хочешь, итобы мы вообще молчали?!

- Так я, оказывается, хочу, итобы вы молиали?!

- Мама, ну что ты так разнервничаласъ? Успокойся, наконец!

2) Atë telefonin e paske marrë shumë zët, tha një rekrut duke dashur të përtërinte bisedën (I. Kadare, Dimri i madh, f. 453).

Видно, здорово допёк тебя этот телебон, если ты так ненавидел, - сказал сидевщий рядом с крестьянином новобранеч, итобы поддержать беседу.

3) Këtu qenka si fillimi i botës - tha Iliri (I. Kadare, Dimri i madh, f. 397). -

Так, наверное, начиналось сотворение мира», ь- - подумал Илир.

С помощью глагольных форм адмиратива (dashkam, qenka, paske marrë) говорящий выражает своё удивление от неожиданных действий. При отсутствии аналогичных форм в русском языке переводчики прибегали к вводным словам оказывается (1), наверное (2) и видно (3). Без использования этих слов, ситуация была бы представленна эмоционально нейтральной. Для иллюстрации сравниваем перевод следующей ситуации:

Njëri ia mbushi përsëri gotën (djalit). 
- Si të duket? - tha shoferi me mustaqe.

- Qenka e hidhur - tha djali... (N. Lera, Bora e fundit, f. 62).

Кіто-то налил ему пива.

- Ну как, нравится тебе? - спросил усатый.

- Оно горькое, - ответил мальиик...

В албанском оригинале мальчик, который впервые попробовал пиво, не ожидал, что оно будет горьким, поэтому его удивление в связи с этим выражается формой адмиратива qenka (e hidhur) в настоящем времени. В переводе эта ситуация осталась эмоционально нейтральной. Эмоциональный нейтралитет данной реплики (Оно горькое) можно было бы избежать, если бы переводчик использовал вводное слово оказывается. Сравните: - *Оно, оказывается, горькое, - ответил мальиик...

Чтобы передать удивление говорящего, переводчики иногда использовали подлинную собственную модальную лексику, название действия / состояния, воспринимаемые как удивление. Например:

- Kam një shishe fare të vogël me raki. Do?

- Ëhë, -tha Beni. - Ku e paske gjetur? (I. Kadare, Dimri i madh, f. 460).

- ... есть немного ракии. Хочешь?

- О-го, - удивилея Бән. Где такое дают?

В албанском тексте собеседник выражает своё удивление формой адмиратива в прошедшем времени paske gjetur (найтu). Перфект адмиративной формы передан русской глагольной формой удивился: O-го, - удивился Бэн. Междометие o-го усиливает модальное значение удивления.

В переводах с русского на албанский нами были замечены некоторые отклонения, являющиеся следствием неправильной интерпретацией оригинала. Сравниваем перевод двух подобных ситуаций: хов)

1) - Да разве братец ихний приехали? Владимир Иваныч? - спрашивает Очумелов... (А. Че-

- Paska ardhur vëllai i gjeneralit, Vladimir Ivaniçi?

2) - Губернатор приехал!

- Верно?

- Сам видел, приехал (М. Горький).

- Ka ardhur vetë guvernatori.

- Vërtet?

- E pashë me sytë e mi!

В оригинале в обоих случаях внезапное появление генерала (1) и губернатора (2) вызвало удивление говорящего. В первом случае перевод точен. Для передачи эмоции удивления переводчик правильно выбрал адмиративную форму в прошедшем времени. Во втором случае, напротив, вместо формы адмиратива использован перфект индикатива. Правильный перевод этой структуры на албанский язык был бы таким: - Paska ardhur vetë guvernatori!

Приводим ещё одну подобную ситуацию из перевода рассказа М. Горького “Макар Чудра»:

Рада говорит : Ты, Лойко, хорошо играешь на скрипке! Кто тебе сделал её такую чуткую и звонкую? -

Rada tha : Ti Llojko i bie mirë violinës. Kush ta ka bërë këtë violinë që bie kaq bukur e ëmbël?

Восклицательный знак в конце русского текста указывает на удивление Рады от игры Лойко на скрипке. Именно эта эмоция не передана в переводе. Настоящее время индикатива (i) bie (играешь) должно было заменено формой адмиратива (i) rënke. Сравните: *Rada tha: "Sa bukur i rënke violinës ti Llojko! Po kush ta ka bërë këtë violinë që tingëlloka kaq bukur e ëmbël?»)

Иногда в переводах с албанского языка используются также формы русского инфинитива, которые в публицистике, помимо неожиданных действий, выражают иронию. Например:

Kush ju lejon tëflisni kështu për vendin tonë? Si u fitoka ose u humbka Shqipëria si një lojë bixhozi? (I. Kadare, Dimri i madh, f. 153).

- Ктоо дал вам право в таком тоне говорить о нашей стране?... Проиграть Албанию, выиграть Албанию? Точно в карточной игре.

В приведённом выше контексте можно использовать аналитическую форму повелительного наклонения (императива) с формообразующей частицей давай: Сравните:

*- Кто дал вам право в таком тоне говорить о нашей стране?... Давай проиграем, выиграем Албанию, точно в карточной игре.

Выводы. Приведённые примеры не исчерпывают разнообразных средств выражения модального значения удивления. Это лишь часть их, наиболее часто используемые средства. Из изложенного видно, что (иерархия) средств выражения модального значения удивления в албанском и русском языках не совпадает. Но для практики перевода не очень важно, выражается ли модальное значение морфологическими, синтаксическими либо лексическими средствами. Важно, чтобы они совпадали функционально. Функционально-семантическая категория адмиратива русского языка и соответствующая ей грамматическая категория адмиратива в албанском языке имеют как общие для двух языков, так и некоторые специфические, свойственные каждому из них, средства выражения. В подавляющем большинстве случаев при переводе отмечается прагматическая тождественность оригиналу. Несовпадение средств выражения модальности адмиратива нередко приводит к нарушению 
прагматического потенциала языковых единиц или к неточному раскрытию адмиративной модальности в переводах. Следовательно, перспективным в рамках русского и албанского языкознания является дальнейший поиск закономерностей перевода конструкций, выражающих адмиративную модальность, и возможных при этом переводческих решений.

\section{Литература}

1. Балли Ш. Общая лингвистика и вопросы французского языка / пер. с франц. - М. : Изд-во иностр. лит., 1955. $-416 \mathrm{c}$.

2. Бондарко A. В. (отв. ред.) Теория функциональной грамматики. Темпоральность. Модальность. - Л. : Наука, 1990. $-263 \mathrm{c}$

3. Виноградов, В. В. Исследования по русской грамматике : Избранные труды. - М. : Наука, 1975. - 559 с.

4. Епифанщева Н. Г. Французский синтаксис (в сопоставлении с синтаксической системой русского языка). - М. : МНЭПУ. 2001. - 196 с.

5. Плунгян В. А. Общая морфология : введение в проблематику. - 3-е изд., испр. и доп. - М. : Либроком, 2010. $-384 \mathrm{c}$

6. Русская грамлатика : в $2 \mathrm{~m}$. / АН СССР, Ин-т рус. яз. - М. : Наука, 1980.

7. Савченко A. A. Тождества и трансформы средств выражения адмиратива во французском и русском языках (сопоставительный и переводческий аспекты) : дис. ... канд. филол. наук : 10.02.05. - СПб. : Санкт-Петербургский гос. ун-т, 2013. - $197 \mathrm{c}$.

8. Demiraj Sh. Gramatikë histtorike e gjuhës shqipe. — Tirana : Tirana University Press, 1986. — 1166 p.

9. Dozon A. Manuel de la langue chkipe ou albanaise. - Paris : Ernest Leroux, 1878. - 350 p.

10. Slobin D., Ayhan A. Tense aspect and modality in the use of the Turkish evidential // Tense and aspect : between semantics and pragmatics. - Amsterdam : John Benjamins Publishing Company, 1982. - P. 185-200.

\section{Источники}

Горький M. Макар Чудра и другие рассказы. - 7-е изд. - М. : Детская литература, 1977. - 190 с.

Чехов А. П. Рассказы и повести. - М. : Правда, 1979. - 640 с.

Blushi K. Në shtëpinë tonë. - Tiranë : $1980 .-224 \mathrm{f}$.

Kadare I. Dimri i madh. - Tiranë : 8 Nëntori, 1973. - 510 f.

Lera N. Bora e fundit : tregime. - Tiranë : Naim Frashëri, 1972. - $160 \mathrm{f}$.

\section{References}

1. Bally, Charles (1955), General linguistics and the French linguistics [Obshhaja lingvistika i voprosy francuzskogo jazyka], Foreign Literature Publishing House, Moscow, 416 p.

2. Bondarko, A. V., ed. (1990), Theory of functional grammar. Temporality. Modality [Teorija funkcional'noj grammatiki. Temporal'nost'. Modal'nost'], Nauka, Leningrad, 263 p.

3. Vinogradov, V. V. (1975), Studies in Russian grammar : Selected Works [Issledovanija po russkoj grammatike : Izbrannyje trudy], Nauka, Moscow, 559 p.

4. Epifanceva, N. G. (2001), French syntax (in comparison with the syntactic system of the Russian language) [Francuzskij sintaksis ( $v$ sopostavlenii s sintaksicheskoj sistemoj russkogo jazyka)], International Independent University of Environmental and Political Sciences, Moscow, 196 p.

5. Plungjan, V. A. (2010), General morphology : introduction to the problematic,3rd ed., rev. and additional [Obshhaja morfologija: Vvedenie v problematiku], Book house (LIBROKOM», Moscow, $384 \mathrm{p}$.

6. The Russian Grammar : in 2 vol. (1980), [Russkaja grammatika : $v 2 t$.], Istitute of the Russian language of Academy of Sciences of USSR, Nauka, Moscow.

7. Savchenko, A. A. (2013), Identities and transformations of the means of expression of the admirative in the French and Russian languages (comparative and translational aspects): Thesis [Tozhdestva i transformy sredstv vyrazhenija admirativa vo francuzskom i russkom jazykakh (sopostavitel'nyj i perevodcheskij aspekty) : dis. ... kand. filol. nauk : 10.02.05], St. Petersburg State Univ., $197 \mathrm{p}$.

8. Demiraj, Shaban. (1986), Historical Grammar of the Albanian Language [Gramatikë histtorike e gjuhës shqipe], Tirana University Press, Tirana, 1166 p.

9. Dozon, A. (1878), Manuel de la langue chkipe ou albanaise, Ernest Leroux (éd.), Paris, 350 p.

10. Slobin, D. \& Ayhan, A. (1982), "Tense aspect and modality in the use of the Turkish evidential», Tense and aspect : between semantics and pragmatics, John Benjamins Publishing Company, Amsterdam, p. 185-200.

Sources

Gorky, M. (1977), Makar Chudra and other stories, 7 th ed. [Makar Chudra i drugije rasskazy. - 7-e izd.], Children's Literature, Moscow, 190 p.

Chekhov, A. P. (1979), Stories and novels [Rasskazy i povesti], Pravda, Moscow, 640 p.

Blushi, K. (1980), In our house [Në shtëpinë tonë], Tirana, $224 \mathrm{p}$.

Kadare, I. (1973), Great winter [Dimri i madh],8 November, Tirana, 510 p.

Lera, N. (1972), The last snow : stories [Bora e fundit : tregime], Naim Frashërri, Tirana, 160 p. 
МИХАЙЛЕНКО-ЗоТо олена Олександрівна, аспірант кафедри російської мови Одеського національного університету імені I. І. Мечникова; Французький бульвар, 24/26, м. Одеса, 65058, Україна; ст. викладач кафедри слов'яно-балканських мов, координатор відділення російської мови Тиранського університету; вул. Ельбасан, м. Тирана, Албанія; тел: + 35542452610 ; e-mail: olena.zoto@gmail.com; ORCID ID: 0000-0001-7733-0217

\section{ДЕЯКІ ЗАСОБИ ВИРАЖЕННЯ АДМІРАТИВНОЇ МОДАЛЬНОСТІ ТА СПОСОБИ ЇЇ ЗБЕРЕЖЕННЯ В ПЕРЕКЛАДІ (НА МАТЕРІАЛІ АЛБАНСЬКОЇ ТА РОСІЙСЬКОЇ МОВ)}

Анотація. Мета статті - виявити специфбічні засоби вираження адміративу, а також визначити деякі можливі перекладацькі рішення. Об'єкт вивчення - функційно-семантична категорія адміративу, яка об'єднує різнорівневі засоби вираження подиву в албанській і російській мовах. Предметом дослідження є інтерпретація модальності адміративу, аналіз подібних і специфічних мовних засобів виражіення модального значення подиву в двох мовах, тотожності й трансформи, використовувані в перекладі. Результатом дослідження стало виявлення того, що засоби вираження адміративу в албанській і російській мовах є різними: в албанській мові засоби вираження подиву об'єднано в граматичній категорії адміративу, в російській же емоцію подиву виражено лексично, здебільшого, вставними словами. Труднощі перекладу модального значення подиву спричинено саме асиметрією засобів вираження сематичної категоpiї адміративності в обох мовах. Висновки. Категорія адміративу, виокремлена в албанській і російській мовах, має як загальні для обох мов, так і деякі специфічні засоби передачі, властиві одній з них. У переважній більшості випадків перекладу відзначається прагматична тотожність оригіналу. Розбіжність засобів передачі адміративної модальності нерідко призводить до порушення прагматичного потенціалу мовних одиниць або до неточного розкриття адміративного значення в перекладах. Практична значимість дослідження полягає в уможливленні встановити основні особливості перекладу семантичний категорії для використання отриманих результатів у викладацькій роботі з підготовки викладачів російської та албанської мов, а також перекладачів з російської мови на албанську і з албанської на російську. Крім того, отримані дані можуть бути використані для вдосконалення комп'ютерних перекладацьких програм 3 російської мови на албанську і навпаки.

Ключові слова: адміратив, функційно-семантична категорія, переклад, об'єктивна модальність, суб'єктивна модальність, російсько-албанський переклад.

Olena O. MIKHAILENKO-ZOTO,

post-graduate student of the Russian language Department, Odessa I. I. Mechnikov National University; Frantsuzskij blvd., 24/26, Odessa, 65058, Ukraine; Senior Lecturer of the Slavonic-Balkan languages department, the Coordinator of the Russian language department of the University of Tirana; Elbasan str., Tirana, Albania;

tel.: +35542452610; e-mail: olena.zoto@gmail.com; ORCID ID: 0000-0001-7733-0217

\section{SOME MEANS OF EXPRESSION OF ADMIRATIVE MODALITY AND METHODS OF ITS CONSERVATION IN TRANSLATION (BASED ON ALBANIAN AND RUSSIAN LANGUAGES)}

Summary. The purpose of the article is to identify specific means of expressing the admirationl, and also to establish some possible translation solutions. The object of this study is a functional-semantic category of the admiration, combining different levels of expression of surprise in the Albanian and Russian languages. The subject of the study is the interpretation of admirative modality, the analysis of similar and specific language means of expressing the modal meaning of surprise in both languages, identities and transforms used in translation. The result of the research was the discovery that the means of admirative expressing in the Albanian and Russian languages are different: in the Albanian language, the means of expressing surprise are combined into the grammatical category of admirative. In addition in Russian the emotion of surprise is expressed lexically, mostly by introductory words. Difficulties of translating the modal meaning of surprise are associated precisely with asymmetry in the means of expressing the semantic category of admiration in both languages. Conclusions. Albanian and Russian admiratives have some common and some specific means. In the overwhelming majority of cases, a pragmatic identity is noted for the original. The mismatch of means for expressing admirative modality often leads to a violation of the pragmatic potential of lingual units or to an inaccurate disclosure of admirative modality in translations. The practical significance of the research is the ability to establish the basic features of the translation of this semantic category for the use of the results obtained in the training of teachers of the Russian and Albanian languages, as well as translators from Russian into Albanian and from Albanian into Russian. In addition, the data obtained can be used to improve computer translation programs from Russian into Albanian and vice versa.

Key words: admirative, functional-semantic category, translation, objective modality, subjective modality, Russian-Albanian translation.

Статтю отримано 2.04.2018 p. 